Published in final edited form as:

Behav Cogn Psychother. 2017 July ; 45(4): 366-381. doi:10.1017/S1352465817000108.

\title{
Same, Same But Different? Cognitive Behavioural Treatment Approaches for Paediatric CFS/ME and Depression
}

\author{
M.E. Loades and \\ Department of Psychology, University of Bath, Bath BA2 7AY \\ T. Chalder \\ Department of Psychological Medicine, Institute of Psychiatry, Psychology and Neuroscience, \\ King's College London
}

\begin{abstract}
Background-Approximately one in three children and young people with chronic fatigue syndrome (CFS/ME) also have probable depression. Cognitive behaviour therapy (CBT) has a growing evidence base as an effective treatment approach for CFS/ME and for depression in this population.
\end{abstract}

\begin{abstract}
Aims-Given the high degree of co-morbidity, this discussion paper aims to compare and contrast CBT for CFS/ME and CBT for depression in children and young people.

Method-The existing literature on CBT for depression and CBT for CFS/ME, in relation to children and young people was reviewed.

Results-Whilst there are commonalities to both treatments, the cognitive behavioural model of CFS/ME maintenance includes different factors and has a different emphasis to the cognitive behavioural model of depression, resulting in different intervention targets and strategies in a different sequence.
\end{abstract}

Conclusions-A collaborative, formulation-driven approach to intervention should inform the intervention targets and treatment strategies.

\section{Keywords}

CBT; CFS/ME; depression; mood; paediatric

\section{Introduction}

The high co-morbidity between depressive symptoms and paediatric chronic fatigue syndrome (CFS), or myalgic encephalomyelitis (ME), has long since been recognized (Garralda, 1992; Jordan et al., 1998). At least 30\% of children and young people with CFS/ME also have probable depression (Bould et al., 2013), which is significantly higher than the point prevalence of depression in the healthy adolescent population of between 2

Correspondence to M.E. Loades, Department of Psychology, University of Bath, Bath BA2 7AY. M.E.Loades@bath.ac.uk. Conflicts of interest: Maria Loades and Trudie Chalder have no conflicts of interest with respect to this publication. 
and 5\% (Zhou et al., 2014). Rates of depression in children with CFS/ME are also higher than the rates of depression in children with other chronic illnesses, for example cystic fibrosis (Walford et al., 1993) and migraine (Smith et al., 2003).

There is diagnostic overlap between depression and CFS/ME. The key diagnostic feature of depression is low mood and/or loss of pleasure in most activities (NICE, 2005). To formally diagnose 'major depressive disorder' (APA, 2013), the depressed mood should be significantly different from the individual's baseline functioning, and have lasted for at least 2 weeks, with evidence of clinically significant distress or reduction in functioning. Fatigue is listed in the diagnostic criteria for depression. Paediatric CFS/ME is defined as 'generalized' fatigue persisting after routine tests and investigations have failed to identify an obvious underlying 'cause' (RCPCH, 2004, p. 28). CFS/ME is characterized by persistent fatigue, which has a significant impact on functioning and is not alleviated by rest; it may be accompanied by joint and muscle pain, headaches, poor concentration, a recurrent sore throat, and flu-like malaise (NICE, 2007). Table 1 provides a comparison of the diagnostic criteria for depression and chronic fatigue syndrome, using the ICD-10 diagnostic criteria published by the World Health Organization (1993).

The temporal relationship between low mood/depression and CFS/ME is unclear. Rimes et al. (2007) reported on four young people who developed CFS/ME, three of whom had at least one psychiatric diagnosis at baseline, and ter Wolbeek et al. (2008) found that fatigue development in adolescent girls at follow-up (4.5 years) was preceded by depressive symptoms at baseline. These studies suggest that depression may temporally predate CFS/ME. However, narrative accounts of young people with CFS/ME who have experienced low mood suggest that it is experienced as resulting from the impact of CFS/ME symptoms on functioning (Taylor et al., 2016).

The combination of low mood and CFS/ME is likely to be detrimental to young people, although the specific consequences are as yet unknown. In adolescents without CFS/ME, experiencing depression is known to increase the likelihood of subsequent depressive episodes, interpersonal difficulties and suicide in adulthood (Fombonne et al., 2001). Although longitudinal studies are lacking, young people with CFS/ME and low mood appear more disabled and experience worse fatigue and more pain than those without depression (Bould et al., 2013). Adults with CFS/ME have a higher risk of completed suicide than the general population, especially in those with a lifetime diagnosis of depression (Roberts et al., 2016). The evidence base does not currently enable any conclusions to be drawn about the impact of low mood and depression on recovery from paediatric CFS/ME (Loades et al., 2016). In adults with CFS/ME, depression has been associated with a worse prognosis in some studies (Darbishire et al., 2003; Flo and Chalder, 2014; Kempke et al., 2010; Tummers et al., 2013; Wearden et al., 2012; White and Naish, 2001), but not in others (Matsuda et al., 2009; Prins et al., 2005; Schreurs et al., 2011). Furthermore, some CFS/ME treatment approaches may be more favourable for adults with co-morbid depression; a meta-analysis of the effectiveness of CBT and graded exercise therapy (GET) showed no significant difference between the treatments in reducing fatigue and remediating functional impairment, although CBT tended to result in greater reductions in depression than GET. 
There are similarities and differences in the treatment approaches for CFS/ME and depression in children and young people. In young people with CFS/ME, there is evidence that CBT is an effective treatment, although at least $20 \%$ of children do not get better within 6 months (Chalder et al., 2010; Gordon et al., 2010; Nijhof et al., 2012; Stulemeijer et al., 2005). NICE also recommends graded exercise therapy (NICE, 2007). Commensurate with the evidence base, the guidelines for treatment for moderate to severe depression (in the absence of CFS/ME) state that young people should be offered 'a specific psychological therapy (individual CBT, interpersonal therapy, family therapy or psychodynamic psychotherapy) that runs for at least 3 months' (NICE, 2015, p. 8). To date, CBT has not proved unequivocally more effective for treating depression in adults than other therapies (Johnsen and Friborg, 2015) and behaviour therapy, for example, may be at least as effective for both adults (Cuijpers et al., 2007) and young people (Hetrick et al., 2015).

Thus the commonality between the evidence-based NICE guidelines for CFS/ME (NICE, 2007) and paediatric depression (NICE, 2015) is that both suggest the use of CBT. This article aims to provide a conceptual and clinical review of the similarities and differences between CBT for CFS/ME and CBT for depression in children and young people. Both formulation and intervention will be considered.

\section{CBT for depression}

The cognitive model of depression (Beck, 1979) posits that depression develops as a result of the activation of negative, unhelpful core beliefs by a precipitating critical incident. These core beliefs are formed as a result of early childhood experiences and pertain to how the individual perceives themselves, others and the world. For example, an experience of critical parenting may lead a child to develop beliefs that they are unlovable and that others are critical. To navigate the world within the constraints of these beliefs, the individual develops a host of dysfunctional assumptions or rules for living (Fennell, 1997) which act as compensatory or protective strategies. The child who believes that they are unlovable may assume that if they can be perfect, then people will love them and not reject them. The precipitating incident is likely to prevent the dysfunctional assumption from being adhered to, therefore activating the negative and unhelpful core belief(s). The core beliefs are reflected in situation specific cognitions, triggered by a range of situations which, through the lens of the core belief, the individual interprets negatively, resulting in negative affect (typically low mood/sadness, but particularly in adolescents, also irritability), unhelpful physiological and cognitive symptoms (e.g. fatigue, anhedonia, lack of concentration) and unhelpful, reinforcing behaviours such as withdrawal from social interactions or from enjoyable and pleasant activities. A vicious cycle of negative thoughts, feelings, behaviours and physiological responses therefore perpetuates the depression, and feedback loops result in the core belief being strengthened (Fig. 1). Thus Beck (1979) postulated that the cognitive symptoms of depression (i.e. depressed thinking) precede the affective symptoms of depression; what is considered central to depression in this model are negative thoughts and beliefs.

Based on the Beckian cognitive behavioural model of depression, CBT for depression typically follows a series of stages, although the rate of progress and form that these take 
varies according to the developmental stage and age of the adolescent (Verduyn et al., 2009). CBT begins with between one and three sessions of assessment and engagement, including collaborative problem formulation, goal setting, and psychoeducation about depression. The work proceeds to emotional recognition and management, and activity scheduling (approximately sessions 4 to 6). Activity scheduling, or behavioural activation, involves strategically scheduling activities from which an individual gains a sense of mastery, achievement or enjoyment (Veale, 2008), thus addressing the behavioural responses that contribute to the maintenance of the depressed mood. At this stage of therapy, the work also includes developing an understanding of the relationship between thoughts, feelings and behaviours. From session 7 onwards, the focus shifts to cognitions, initially through the identification of common thinking biases, and subsequently, through learning to question and test unhelpful thinking (with a focus on hopelessness and helplessness), through Socratic dialogue and behavioural experiments. Problem-solving skills may also be included. Work on beliefs and dysfunctional assumptions may then proceed, with therapy ending with relapse prevention. Therapy would usually last for approximately 16 sessions (Verduyn et al., 2009), and at least nine sessions of CBT for depression has been shown to be 2.5 times more likely to result in adequate response to treatment (Emslie et al., 2010).

An alternative cognitive model of depression is the hopelessness theory (Abramson et al., 1989), based on Seligman's work on attributions and learned helplessness (Seligman, 1975). When a personally relevant negative event occurs, people who have a depressive attributional style (that is, a tendency to attribute negative life events to internal, stable and global causes) are more likely to develop low mood as a result of their inferential thinking that negative consequences will result from the negative event, and that the negative event occurring means that they are worthless or fundamentally flawed. This attributional style thereby poses a vulnerability for developing depression and serves to maintain it.

In contrast, behavioural models of depression (Lewinsohn and Graf, 1973) emphasize the maintenance of low mood by the reinforcement of depressive behaviours, and lack of reinforcement of non-depressed behaviours. Vulnerability to developing depression and overcoming depression depend on social skill as well as environmental factors such as the range and availability of events that are potentially reinforcing. Behavioural Activation for Treating Depression (Lejuez et al., 2011) aims to lift mood and build resilience by increasing an individual's focus on their core values, and linking these to daily activities, which are explicitly planned and scheduled. This has been provisionally trialled in depressed adolescents with good outcomes (Pass et al., 2015, 2016).

\section{CBT for CFS/ME}

There are a number of cognitive behavioural models of CFS/ME. The cognitive behavioural model of CFS/ME (Browne and Chalder, 2006; Mackenzie and Wray, 2013) posits that physical factors (e.g. infections), social factors (e.g. lifestyle and stressful life events) and emotional factors (such as personality and mood) may contribute to the development of $\mathrm{CFS} / \mathrm{ME}$. The symptoms of CFS/ME, including for example fatigue and muscle pain, result in individuals avoiding activity in an attempt to feel better. Resting more and becoming more unfit through deconditioning can exacerbate symptoms, which, when combined with an 
increase focus on symptoms, lead to fear of undertaking activity which might exacerbate symptoms, and fears that the symptoms mean the individual is very ill, resulting in further reductions in activity. This can generate feelings of frustration and worry, as well as a sense of helplessness and loss of control, which may result in either over-activity or inactivity as a compensatory strategy, both of which result in a worsening of the symptoms. Wessely's model of CFS/ME postulates that a heightened focus on illness (and physiological symptoms perceived to be related to illness) reinforces an individual's belief that they have an acute and potentially dangerous disease, and as a result, they decrease their activity levels (Butler, Chalder, Ron and Wessely, 1991). There is increasing evidence in adults that cognitions, such as the interpretation of the meaning of the symptoms and focusing on the symptoms, are associated with symptom severity (Fernie et al., 2015; Maher-Edwards et al., $2011,2012)$ although this research has yet to be extended to adolescent populations. There is also evidence for beliefs about emotions leading to emotional suppression in adults with CFS/ME (Rimes and Chalder, 2010; Rimes et al., 2016), which could contribute to vulnerability to problem development and to maintenance (Surawy et al., 1995). Personality traits such as striving for high standards and neglecting one's own needs as predisposing vulnerability factors have been incorporated into this model (Surawy et al., 1995).

CBT for CFS/ME in adolescents typically consists of a behavioural element, which aims to gradually and consistently increase activity, and a cognitive component, which targets thoughts, assumptions and beliefs about the young person's illness and symptoms (Mackenzie and Wray, 2013). The behavioural component may focus on sleep habits and interventions to promote sleep quality (for example, anchoring the bedtime and wake-up time), as well as monitoring high energy activity and boom-and-bust cycles, aiming to do instead do a consistent amount of high energy activity every day, regardless of symptoms, and gradually increasing this (Browne and Chalder, 2006). The CBT approaches to CFS/ME in adolescents (Lloyd et al., 2012; Nijhof et al., 2012) have been predominantly behavioural; the focus is on behavioural change through activity management. Cognitive misinterpretations such as the exploration and challenging of the 'meaning' of the symptoms are addressed as and when necessary. This is in contrast to the centrality of cognition in traditional cognitive therapy (Beck, 1979). CBT for CFS/ME may, where necessary, include work on anxiety and depression (Lloyd et al., 2012), although this is not the predominant focus. Typical duration, based on published studies, varies significantly, from five sessions over 6 months (Kawatani et al., 2011) to 18 sessions (Al-Haggar et al., 2006), with European studies providing, for example, 21 interactive internet-delivered modules (Nijhof et al., 2012) or 15 hourly face-to-face sessions (Chalder et al., 2002).

In adults, various published CBT for CFS/ME treatment protocols have adopted different aims and foci, including cognitive and behavioural elements but placing differing emphasis on these components. For example, in the PACE trial, the CBT package aimed to improve levels of functioning as a primary outcome (Burgess and Chalder, 2004). The cognitive component addresses fearful thoughts about activity, fear avoidance beliefs, and perfectionist thoughts and beliefs that feed boom-and-bust cycles. The behavioural component includes activity management and sleep hygiene, as well as graded exposure to anxiety-provoking situations where necessary. In contrast, a Dutch CBT treatment protocol, with the aim of recovery from fatigue, included a prescribed physical activity programme, addressing 
unhelpful thoughts and beliefs about exercise specifically within this (Knoop and Bleijenberg, 2010). It also emphasizes empowering patients, addressing low self-efficacy regarding fatigue, and tackles the role of symptom focus as a maintenance factor (WormSmeitink et al., 2016). Although both packages had good outcomes, the Dutch approach was more effective (Worm-Smeitink et al., 2016).

\section{Comparison of CBT treatments}

\section{Commonalities}

Both CBT for depression (CBT-D) and CBT for CFS/ME (CBT-CFS) share the same underpinning ethos. They are collaborative, working together with the young person and their family as a team, rather than taking an expert-patient stance (Stallard, 2005). Furthermore, the approach is one of empirical discovery; the therapist does not assume that they know the answers, but rather, works with the young person to seek to find out how the world works, for example through testing out an assumption via a behavioural experiment (Fuggle et al., 2013).

There are further similarities with regard to what the therapist might be expected to do; therapy commences with engagement and alliance building behaviours such as validating feelings, active listening, being nice and expressing care (Baylis et al., 2011), and involves psychoeducation and socialization to the CBT model. Therapy sessions are structured, using an agenda. At the end of each session, between-session tasks are collaboratively developed, emerging from the content of the session, with the aim of helping to generalize and apply learning from therapy in daily life. There is also an emphasis on self-monitoring to enable the young person to recognize patterns in thoughts/feelings/behaviour/physiological symptoms, and to spot triggers for specific difficulties, which would also further inform the shared formulation and enable the identification of treatment targets. Therapeutic work is goal focused (Verduyn et al., 2009). During therapy, parents are included when it is necessary and/or helpful to do so, and parental involvement may take a variety of forms including the roles of co-therapist or co-client (Stallard, 2005).

\section{Differences}

There are a number of differences between CBT-D and CBT-CFS that distinguish the approaches (see Table 2):

(1) Formulation of problem development is different, specifically with regard to precipitating factors. In CFS/ME, precipitating factors are assumed to include infections with an immune response, and subsequent physical deconditioning (White et al., 2001). However, evidence for deconditioning is questionable as CFS/ME patients have been found to be similarly deconditioned to sedentary controls, and a recent mediation analysis showed that in adults, change in fear avoidance beliefs rather than physical function was the strongest mediator of treatment outcome (Chalder et al., 2015). Depression tends to be predicted by a combination of significant life events, an emotional personality and past psychiatric history. 
(2) Therapeutic goals would be expected to be different in CBT-D versus CBT-CFS. In CBT-D, the overarching goal tends to be mood improvement, whilst CBTCFS aims to remediate fatigue and/or improve functioning. However, commensurate with the collaborative CBT approach, goals are individualized, and therefore could be wide-reaching and overlapping.

(3) The impact of activity in CFS/ME is different to what would be expected in depression. Although fatigue and lack of energy are expected in both, fatigue in depression (mental and physical) can be alleviated by activity and exercise, whereas in CFS/ME, excessive physical exertion tends to cause symptom exacerbation, resulting in activities that may previously have been pleasurable and positively reinforcing being experienced as aversive and negatively reinforcing (Taylor et al. 2016).

(4) The way in which activity is tackled is different. In CBT-D, the aim is to increase activity early on in therapy with behavioural activation (Verduyn et al., 2009). This breaks the negative cycle of inactivity and lack of motivation, thereby improving mood. Activity scheduling initially involves monitoring to determine the current activity levels, alongside rating mood. Subsequently, activities that give a sense of enjoyment and/or achievement are purposefully planned and undertaken. In CBT-CFS, the initial focus is also on activity, which is initially monitored, with the emphasis on distinguishing high-energy versus low-energy activities (without necessarily monitoring mood). The activity management approach (Browne and Chalder, 2006; NICE, 2007) aims to establish a baseline of activities that a young person is able to do every day, by determining the midpoint between what they are able to do on the best day and what they are able to do on the worst day. Once this baseline has been established, the young person would then gradually increase the amount of activity, by approximately $10 \%$ every fortnight. This may initially mean reducing the amount of activities they are doing, at least on some days of the week, to achieve a consistent level of activity across days. Activity scheduling (Rimes and Chalder, 2015) would focus on planning rests and including a range of different activities in the programme.

(5) The cognitive focus of the work is also different. In CBT-D, the focus is on negative automatic thoughts, assumptions and beliefs that would most closely be associated with depression such as negative thoughts about the self, others and the future (Beck, 1979), whilst in CBT-CFS, the focus is on negative automatic thoughts, assumptions and beliefs that may be maintaining disability and symptoms, such as fear avoidance beliefs and catastrophic thinking about symptoms and the impact of activity (Rimes et al., 2014). Consistent with this, in adults, CFS/ME patients have been found to be primarily concerned with their health problems (Hughes et al., 2016), whereas depressed patients' cognitions were found to be focused on negative views of themselves (Moss-Morris and Petrie, 2001). It is not known to what extent the same trends exist in young people. Furthermore, cognitive biases such as symptom focusing in CFS/ME can be tackled directly with attentional training (Worm-Smeitink et al., 2016), 
whereas the biases in depression are more typically addressed by noticing, labelling and challenging the thinking patterns in specific situations (Verduyn et al., 2009).

\section{Discussion}

Despite differences in the cognitive behavioural models of CFS and depression, primarily the extent to which cognitions are seen as precipitating the problem, there are fundamental underlying similarities with regard to the perpetuation of the difficulties in both models with interactions between cognitions, behaviour, emotions and physiological symptoms serving to reinforce and exacerbate each other. These differences imply that the process of collaborative formulation, whilst similar at maintainence level, would be different in terms of understanding problem onset and vulnerability. Given the significant impact that CFS/ME has on functioning (i.e. behaviour) of young people, incorporating elements of the behavioural model of depression and the impact of the physical illness on reinforcement from the environment could be useful. An added benefit of this approach is that it could help a young person to avoid or challenge internal, global and stable attributions, instead formulating their difficulties as a temporary and understandable consequence of a chronic illness which has a significant impact on their behaviour (activity) in their lives and for which they are not to blame. This important former attributional style has been found to be related to both fatigue and the severity of depression in a community sample of adults (Chalder et al., 1996). When working with young people with both depression and CFS/ME, a shared and idiosyncratic formulation approach would seem judicious, drawing on elements of the cognitive and behavioural models and integrating them in a meaningful way (see Fig. 3 for an example).

The current evidence does not allow robust conclusions to be drawn about whether tackling CFS/ME might alleviate depression, or whether a more integrated treatment approach is preferable. No studies have rigorously tested CBT for co-morbid depression in paediatric CFS/ME (Loades et al., 2016), although there are initial indications from a case study (Loades, 2015) that good outcomes can be achieved using a formulation-driven approach. Pragmatically, if a young person is low in mood but feels motivated, able to engage in, and hopeful about the outcome of CBT-CFS, then treatment could start with this focus. If the level of depression, and the associated lack of motivation and degree of hopelessness and helplessness is such that it is likely to impact on a young person's ability to engage in CBTCFS, then it would be important to address both CFS/ME and depression concomitantly. In instances where a young person's depression is overwhelming and includes a significant degree of suicidal ideation, treating the depression and alleviating the risk would be the most judicious course of action, before attempting to treat the CFS/ME.

There are possible ways to integrate the two treatment approaches. For example, in CBT for CFS/ME, high-energy activity would be limited to a certain amount that an individual could manage to do every day, regardless of whether it was a good or bad day. Behaviour activation (CBT-D) could still be utilized by taking account of (1) scheduling high-energy activites that give a sense of enjoyment and/or achievement to fit within this daily limit, and (2) identifying low-energy activites that give a sense of enjoyment and achievement. 
Focusing on a broader range of negative cognitions than usual in CBT-CFS, beyond those specifically related to illness and activity, would be an important adaptation to incorporate more standard CBT-D thought catching and challenging. Adapting CBT for fatigue, which may well be an issue in depression as well as in CFS/ME, for example by reducing the length of sessions, taking breaks during sessions, more repetition of material and supplementing verbal discussions with written summaries, would also be important. There are overlaps between the Surawy model of CFS and models of depression, and it may be that if core beliefs were more explicitly tackled within a CFS/ME approach, individuals would be less prone to relapse. Mindfulness-based CBT (MBCT), which has good evidence of effectiveness as a treatment for relapsing depression in adults (Piet and Hougaard, 2011), has been applied in CFS/ME patients still experiencing excessive fatigue following CBT for CFS (Rimes and Wingrove, 2013). The latter study found that unhelpful beliefs about emotions, catastrophic thinking about fatigue and all-or-nothing thinking patterns improved more in the MBCT group compared with waiting list controls. These factors might reasonably be expected to be more problematic in those CFS/ME patients who are also depressed, and therefore MBCT could make a promising avenue for intervention, but is yet to be applied to young people with $\mathrm{CFS} / \mathrm{ME}$.

\section{Conclusion}

In this paper, we have argued that CBT is an evidence-based treatment for both CFS/ME and depression in children and young people. There are both similarities in the approaches, but also key differences, such as onset formulation, how activity is managed, and which cognitions are targeted. When working with a young person with depression and CFS/ME, clinicians should take a formulation-driven approach to determining where to intervene, and to approach behavioural activation cautiously, incorporating the principles of a graded activity management programme to circumvent boom-and-bust cycles. It is also important for clinicians to consider broadening their focus on negative cognitions beyound those about activity, physical symptoms and illness, to include more global patterns of negative thinking about the self, others, the world and the future.

\section{Acknowledgements}

None.

Financial support: M.L. received research capability funding from the Royal United Hospital in Bath.

\section{References}

Abramson LY, Metalsky GI, Alloy LB. Hopelessness depression: a theory-based subtype of depression. Psychological Review. 1989; 96:358.

Al-Haggar MS, Al-Naggar ZA, Abdel-Salam MA. Biofeedback and cognitive behavioral therapy for Egyptian adolescents suffering from chronic fatigue syndrome. Journal of Pediatric Neurology. 2006; 4:161.

American Psychiatric Association (APA). Diagnostic and Statistical Manual of Mental Disorders: DSM-5. Washington, DC: American Psychiatric Association; 2013.

Baylis PJ, Collins D, Coleman H. Child alliance process theory: a qualitative study of a child centred therapeutic alliance. Child and Adolescent Social Work Journal. 2011; 28:79-95. DOI: 10.1007/ s10560-011-0224-2 
Beck, AT. Cognitive Therapy of Depression. Guilford Press; 1979.

Bould H, Collin SM, Lewis G, Rimes KA, Crawley E. Depression in paediatric chronic fatigue syndrome. Archives of Disease in Childhood. 2013; 98:425-428. DOI: 10.1136/ archdischild-2012-303396 [PubMed: 23619200]

Browne T, Chalder T. Chronic fatigue syndrome. Psychiatry. 2006; 5:48-51. DOI: 10.1383/psyt. 2006.5.2.48

Burgess, M., Chalder, T. [accessed September 2016] PACE manual for therapists. Cognitive behaviour therapy for CFS/ME. 2004. http://www.wolfson.qmul.ac.uk/images/pdfs/3.cbt-therapist-manual.pdf

Butler S, Chalder T, Ron M, Wessely S. Cognitive behaviour therapy in chronic fatigue syndrome. Journal of Neurology, Neurosurgery and Psychiatry. 1991; 54:153-158.

Chalder T, Deary V, Husain K, Walwyn R. Family-focused cognitive behaviour therapy versus psychoeducation for chronic fatigue syndrome in 11- to 18-year-olds: a randomized controlled treatment trial. Psychological Medicine. 2010; 40:1269-1279. DOI: 10.1017/S003329170999153X [PubMed: 19891804]

Chalder T, Goldsmith KA, White PD, Sharpe M, Pickles AR. Rehabilitative therapies for chronic fatigue syndrome: a secondary mediation analysis of the PACE trial. The Lancet Psychiatry. 2015; 2:141-152. DOI: 10.1016/s2215-0366(14)00069-8 [PubMed: 26359750]

Chalder T, Power M, Wessely S. Chronic fatigue in the community: 'a question of attribution'. Psychological Medicine. 1996; 26:791-800. [PubMed: 8817714]

Chalder T, Tong J, Deary V. Family cognitive behaviour therapy for chronic fatigue syndrome: an uncontrolled study. Archives of Disease in Childhood. 2002; 86:95-97. [PubMed: 11827901]

Cuijpers P, van Straten A, Warmerdam L. Behavioral activation treatments of depression: a metaanalysis. Clinical Psychology Review. 2007; 27:318-326. [PubMed: 17184887]

Darbishire L, Ridsdale L, Seed PT. Distinguishing patients with chronic fatigue from those with chronic fatigue syndrome: a diagnostic study in UK primary care. The British Journal of General Practice. 2003; 53:441-445. [PubMed: 12939888]

Emslie GJ, Mayes T, Porta G, Vitiello B, Clarke G, Wagner KD, et al. Treatment of Resistant Depression in Adolescents (TORDIA): week 24 outcomes. American Journal of Psychiatry. 2010; 167:782-791. DOI: 10.1176/appi.ajp.2010.09040552 [PubMed: 20478877]

Fennell MJV. Low self-esteem: a cognitive perspective. Behavioural and Cognitive Psychotherapy. 1997; 25:1-26. DOI: 10.1017/S1352465800015368

Fernie BA, Maher-Edwards L, Murphy G, Nikčević AV, Spada MM. The metacognitions about symptoms control scale: development and concurrent validity. Clinical Psychology and Psychotherapy. 2015; 22:443-449. [PubMed: 24899521]

Flo E, Chalder T. Prevalence and predictors of recovery from chronic fatigue syndrome in a routine clinical practice. Behaviour Research and Therapy. 2014; 63:1-8. DOI: 10.1016/j.brat.2014.08.013 [PubMed: 25222752]

Fombonne E, Wostear G, Cooper V, Harrington R, Rutter M. The Maudsley long-term follow-up of child and adolescent depression. 1. Psychiatric outcomes in adulthood. British Journal of Psychiatry. 2001; 179:210-217. [PubMed: 11532797]

Fuggle, P., Dunsmuir, S., Curry, V. CBT with Children, Young People and Families. London: SAGE Publications Ltd; 2013.

Garralda ME. Severe chronic fatigue syndrome in childhood: a discussion of psychopathological mechanisms. European Child and Adolescent Psychiatry. 1992; 1:111-118. DOI: 10.1007/ BF02091794

Gordon BA, Knapman LM, Lubitz L. Graduated exercise training and progressive resistance training in adolescents with chronic fatigue syndrome: a randomized controlled pilot study. Clinical Rehabilitation. 2010; 24:1072-1079. DOI: 10.1177/0269215510371429 [PubMed: 20605858]

Hetrick SE, Cox GR, Fisher CA, Bhar SS, Rice SM, Davey CG, Parker AG. Back to basics: could behavioural therapy be a good treatment option for youth depression? A critical review. Early Intervention in Psychiatry. 2015; 9:93-99. DOI: 10.1111/eip.12142 [PubMed: 24698212]

Hughes A, Hirsch C, Chalder T, Moss-Morris R. Attentional and interpretive bias towards illnessrelated information in chronic fatigue syndrome: a systematic review. British Journal of Health Psychology. 2016; 21:741-763. DOI: 10.1111/bjhp.12207 [PubMed: 27329758] 
Johnsen TJ, Friborg O. The effects of cognitive behavioral therapy as an anti-depressive treatment is falling: A meta-analysis. Psychological Bulletin. 2015; 141:747. [PubMed: 25961373]

Jordan KM, Landis DA, Downey MC, Osterman SL, Thurm AE, Jason LA. Chronic fatigue syndrome in children and adolescents: a review. Journal of Adolescent Health. 1998; 22:4-18. DOI: 10.1016/ S1054-139X\%2897\%2900212-7 [PubMed: 9436061]

Kawatani J, Mizuno K, Shiraishi S, Takao M, Joudoi T, Fukuda S, et al. Cognitive dysfunction and mental fatigue in childhood chronic fatigue syndrome - a 6-month follow-up study. Brain and Development. 2011; 33:832-841. DOI: 10.1016/j.braindev.2010.12.009 [PubMed: 21530119]

Kempke S, Goossens L, Luyten P, Bekaert P, Van Houdenhove B, Van Wambeke P. Predictors of outcome in a multi-component treatment program for chronic fatigue syndrome. Journal of Affective Disorders. 2010; 126:174-179. DOI: 10.1016/j.jad.2010.01.073 [PubMed: 20167377]

Knoop, JA., Bleijenberg, G. Het chronisch vermoeidheidssyndroom: Behandelprotocol cognitieve gedragstherapie voor CVS. Bohn Stafleu van Loghum; 2010.

Lejuez C, Hopko DR, Acierno R, Daughters SB, Pagoto SL. Ten year revision of the brief behavioral activation treatment for depression: revised treatment manual. Behavior Modification. 2011; 35:111-161. [PubMed: 21324944]

Lewinsohn PM, Graf M. Pleasant activities and depression. Journal of Consulting and Clinical Psychology. 1973; 41:261. [PubMed: 4147832]

Lloyd S, Chalder T, Rimes KA. Family-focused cognitive behaviour therapy versus psycho-education for adolescents with chronic fatigue syndrome: long-term follow-up of an RCT. Behaviour Research and Therapy. 2012; 50:719-725. DOI: 10.1016/j.brat.2012.08.005 [PubMed: 22985998]

Loades M. The cognitive behavioral treatment of depression and low self-esteem in the context of pediatric chronic fatigue syndrome (CFS/ME): a case study. Journal of Child and Adolescent Psychiatric Nursing. 2015; 28:165-174. [PubMed: 26470755]

Loades ME, Sheils EA, Crawley E. Treatment for paediatric chronic fatigue syndrome or myalgic encephalomyelitis (CFS/ME) and comorbid depression: a systematic review. BMJ Open. 2016; 6:e012271.doi: 10.1136/bmjopen-2016-012271

Mackenzie C, Wray A. Chronic fatigue syndrome in children and young people. Paediatrics and Child Health. 2013; 23:35-39. DOI: 10.1016/j.paed.2012.10.001

Maher-Edwards L, Fernie BA, Murphy G, Wells A, Spada MM. Metacognitions and negative emotions as predictors of symptom severity in chronic fatigue syndrome. Journal of Psychosomatic Research. 2011; 70:311-317. [PubMed: 21414450]

Maher-Edwards L, Fernie BA, Murphy G, Nikcevic AV, Spada MM. Metacognitive factors in chronic fatigue syndrome. Clinical Psychology \& Psychotherapy. 2012; 19:552-557. [PubMed: 21567656]

Matsuda Y, Matsui T, Kataoka K, Fukada R, Fukuda S, Kuratsune H, et al. A two-year follow-up study of chronic fatigue syndrome comorbid with psychiatric disorders. Psychiatry and Clinical Neurosciences. 2009; 63:365-373. DOI: 10.1111/j.1440-1819.2009.01954.x [PubMed: 19566769]

Moss-Morris R, Petrie KJ. Discriminating between chronic fatigue syndrome and depression: a cognitive analysis. Psychological Medicine. 2001; 31:469-479. [PubMed: 11305855]

National Institute for Health and Care Excellence (NICE). Depression in children and young people: Identification and management in primary, community and secondary care. 2005. https:// www.nice.org.uk/guidance/cg28

National Institute for Health and Care Excellence (NICE). Chronic fatigue syndrome/myalgic encephalomyelitis (or encephalopathy): Diagnosis and management of CFS/ME in adults and children. 2007. https://www.nice.org.uk/guidance/cg53

National Institute for Health and Care Excellence (NICE). Depression in children and young people: Psychological interventions for mild depression and pharmacological interventions for moderate to severe depression. 2015. (update). https://www.nice.org.uk/guidance/cg28

Nijhof SL, Bleijenberg G, Uiterwaal CS, Kimpen JL, van de Putte EM. Effectiveness of internet-based cognitive behavioural treatment for adolescents with chronic fatigue syndrome (FITNET): a randomised controlled trial. The Lancet. 2012; 379:1412-1418.

Pass L, Brisco G, Reynolds S. Adapting brief Behavioural Activation (BA) for adolescent depression: a case example. The Cognitive Behaviour Therapist. 2015; 8doi: 10.1017/s1754470x15000446 
Pass L, Whitney H, Reynolds S. Brief behavioral activation for adolescent depression: working with complexity and risk. Clinical Case Studies. 2016; 15:360-375. DOI: 10.1177/1534650116645402

Piet J, Hougaard E. The effect of mindfulness-based cognitive therapy for prevention of relapse in recurrent major depressive disorder: a systematic review and meta-analysis. Clinical Psychology Review. 2011; 31:1032-1040. [PubMed: 21802618]

Prins J, Bleuenberg G, Rouweler EK, Van der Meer JW. Effect of psychiatric disorders on outcome of cognitive-behavioural therapy for chronic fatigue syndrome. British Journal of Psychiatry. 2005; 187:184-185. [PubMed: 16055833]

Royal College of Paediatrics and Child Health (RCPCH). [last accessed February 2017] Evidence Based Guideline for the Management of CFS/ME (Chronic Fatigue Syndrome/ Myalgic Encephalopathy) in Children and Young People. 2004. Available at: http://www.rcpch.ac.uk/rcpchguidelines-and-standards-clinical-practice\#cfs-me

Rimes K, Ashcroft J, Bryan L, Chalder T. Emotional suppression in chronic fatigue syndrome: experimental study. Health Psychology. 2016; 35:979-986. DOI: 10.1037/hea0000341 [PubMed: 27183308]

Rimes K, Chalder T. The Beliefs about Emotions Scale: validity, reliability and sensitivity to change. Journal of Psychosomatic Research. 2010; 68:285-292. DOI: 10.1016/j.jpsychores.2009.09.014 [PubMed: 20159215]

Rimes, K., Chalder, T. Overcoming Chronic Fatigue in Young People: A Cognitive-Behavioural SelfHelp Guide. Routledge; 2015.

Rimes K, Goodman R, Hotopf M, Wessely S, Meltzer H, Chalder T. Incidence, prognosis, and risk factors for fatigue and chronic fatigue syndrome in adolescents: a prospective community study. Pediatrics. 2007; 119:e603-609. DOI: 10.1542/peds.2006-2231 [PubMed: 17332180]

Rimes K, Wingrove J. Mindfulness-based cognitive therapy for people with chronic fatigue syndrome still experiencing excessive fatigue after cognitive behaviour therapy: a pilot randomized study. Clinical Psychology \& Psychotherapy. 2013; 20:107-117. DOI: 10.1002/cpp.793 [PubMed: 21983916]

Rimes K, Wingrove J, Moss-Morris R, Chalder T. Competences required for the delivery of high and low-intensity cognitive behavioural interventions for chronic fatigue, chronic fatigue syndrome/ME and irritable bowel syndrome. Behavioural and Cognitive Psychotherapy. 2014; 42:760-764. DOI: 10.1017/S1352465814000290 [PubMed: 24832606]

Roberts E, Wessely S, Chalder T, Chang C-K, Hotopf M. Mortality of people with chronic fatigue syndrome: a retrospective cohort study in England and Wales from the South London and Maudsley NHS Foundation Trust Biomedical Research Centre (SLaM BRC) Clinical Record Interactive Search (CRIS) Register. The Lancet. 2016; 387:1638-1643. DOI: 10.1016/ s0140-6736(15)01223-4

Schreurs KMG, Veehof MM, Passade L, Vollenbroek-Hutten MMR. Cognitive behavioural treatment for chronic fatigue syndrome in a rehabilitation setting: Effectiveness and predictors of outcome. Behaviour Research and Therapy. 2011; 49:908-913. DOI: 10.1016/j.brat.2011.09.004 [PubMed: 21982345]

Seligman, ME. Helplessness: On Depression, Development, and Death. WH Freeman, Times Books, Henry Holt and Co.; 1975.

Smith MS, Martin-Herz SP, Womack WM, Marsigan JL. Comparative study of anxiety, depression, somatization, functional disability, and illness attribution in adolescents with chronic fatigue or migraine. Pediatrics. 2003; 111:e376-381. [PubMed: 12671155]

Stallard, P. A Clinician's Guide to Think Good Feel Good: the Use of CBT with Children and Young People. Chichester: John Wiley; 2005.

Stulemeijer M, de Jong LW, Fiselier TJ, Hoogveld SW, Bleijenberg G. Cognitive behaviour therapy for adolescents with chronic fatigue syndrome: randomised controlled trial. British Medical Journal. 2005; 330:14.doi: 10.1136/bmj.38301.587106.63 [PubMed: 15585538]

Surawy C, Hackmann A, Hawton K, Sharpe M. Chronic fatigue syndrome: a cognitive approach. Behaviour Research and Therapy. 1995; 33:535-544. DOI: 10.1016/0005-7967(94)00077-W [PubMed: 7598674] 
Taylor A, Loades M, Brigden A, Collin S, Crawley E. 'It's personal to me': A qualitative study of depression in young people with CFS/ME. Clinical Child Psychology and Psychiatry. 2016; doi: $10.1177 / 1359104516672507$

ter Wolbeek M, van Doornen LJ, Kavelaars A, Heijnen CJ. Predictors of persistent and new-onset fatigue in adolescent girls. Pediatrics. 2008; 121:e449-457. DOI: 10.1542/peds.2007-1093 [PubMed: 18310166]

Tummers M, Knoop H, Van Dam A, Bleijenberg G. Moderators of the treatment response to guided self-instruction for chronic fatigue syndrome. Journal of Psychosomatic Research. 2013; 74:373377. DOI: 10.1016/j.jpsychores.2013.01.007 [PubMed: 23597323]

Veale D. Behavioural activation for depression. Advances in Psychiatric Treatment. 2008; 14:29-36. DOI: 10.1192/apt.bp.107.004051

Verduyn, C., Rogers, J., Wood, A. Depression: Cognitive Behaviour Therapy with Children and Young People. Taylor and Francis; 2009.

Walford GA, Nelson WM, McCluskey DR. Fatigue, depression, and social adjustment in chronic fatigue syndrome. Archives of Disease in Childhood. 1993; 68:384-388. [PubMed: 8096688]

Wearden AJ, Dunn G, Dowrick C, Morriss RK. Depressive symptoms and pragmatic rehabilitation for chronic fatigue syndrome. British Journal of Psychiatry. 2012; 201:227-232. DOI: 10.1192/bjp.bp. 111.107474 [PubMed: 22844025]

White PD, Naish VA. Graded exercise therapy for chronic fatigue syndrome. Physiotherapy. 2001; 87(6):285-288.

White PD, Thomas JM, Kangro HO, Bruce-Jones WD, Amess J, Crawford DH, et al. Predictions and associations of fatigue syndromes and mood disorders that occur after infectious mononucleosis. The Lancet. 2001; 358:1946-1954.

World Health Organization. [last accessed February 2017] The ICD-10 classification of mental and behavioural disorders: diagnostic criteria for research. 1993. Available at: http://www.who.int/ classifications/icd/en/GRNBOOK.pdf

Worm-Smeitink M, Nikolaus S, Goldsmith K, Wiborg J, Ali S, Knoop H, Chalder T. Cognitive behaviour therapy for chronic fatigue syndrome: differences in treatment outcome between a tertiary treatment centre in the United Kingdom and the Netherlands. Journal of Psychosomatic Research. 2016; 87:43-49. DOI: 10.1016/j.jpsychores.2016.06.006 [PubMed: 27411751]

Zhou X, Michael KD, Liu Y, Del Giovane C, Qin B, Cohen D, et al. Systematic review of management for treatment-resistant depression in adolescents. BMC Psychiatry. 2014; 14:340.doi: 10.1186/ s12888-014-0340-6 [PubMed: 25433401] 


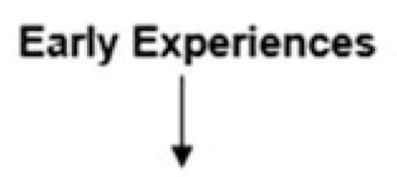

Core beliefs

About the self, others and the world
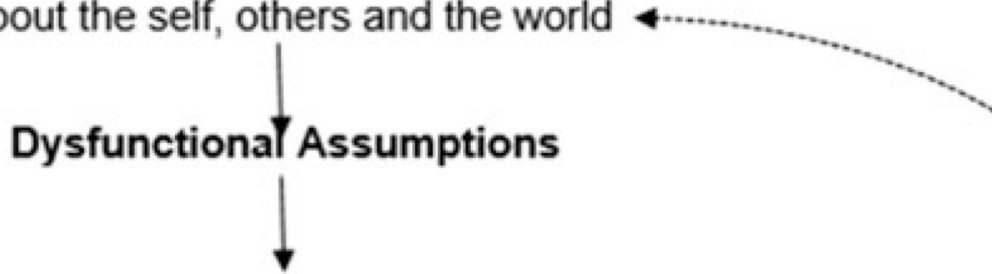

Critical incident

Activates core beliefs by threatening or violating assumptions

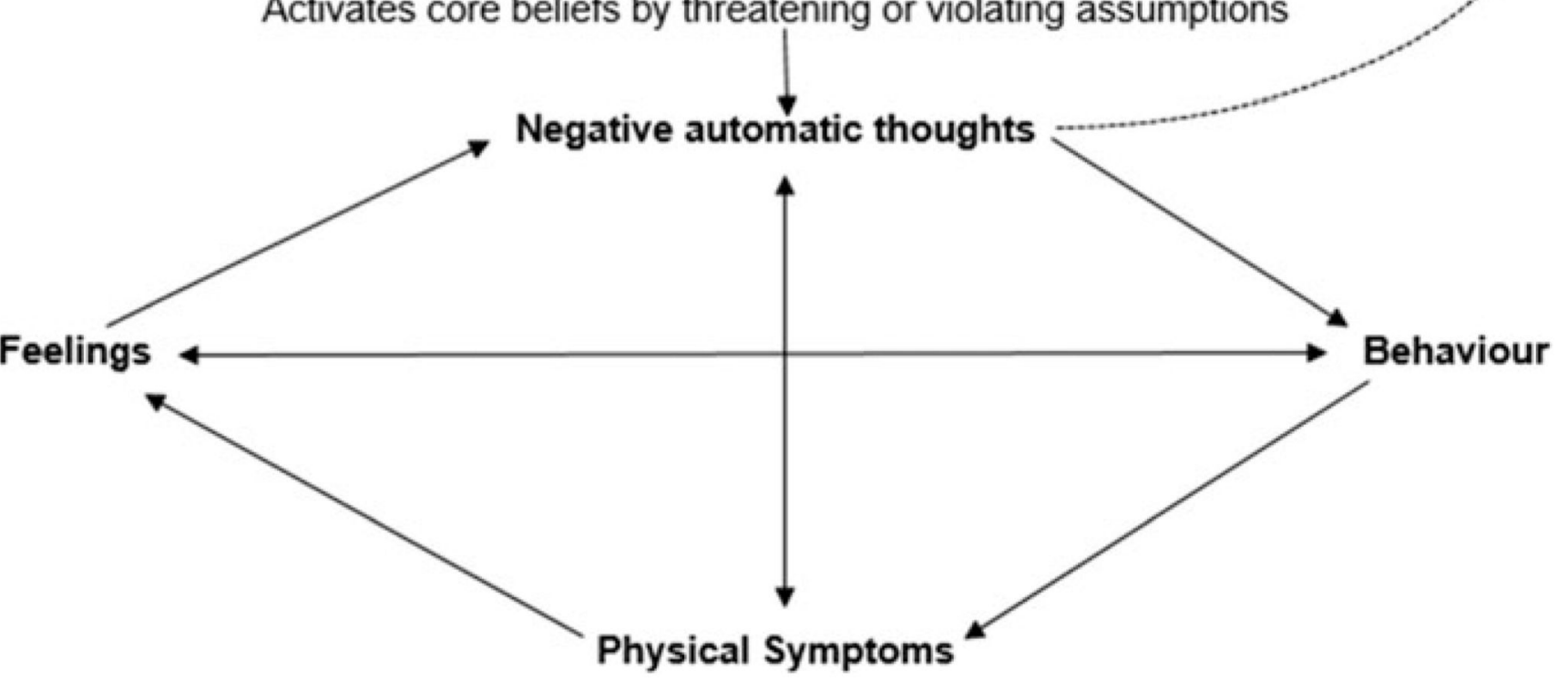

Figure 1.

Longitudinal formulation of depression (based on Beck, 1979) 


\section{Early Experiences}

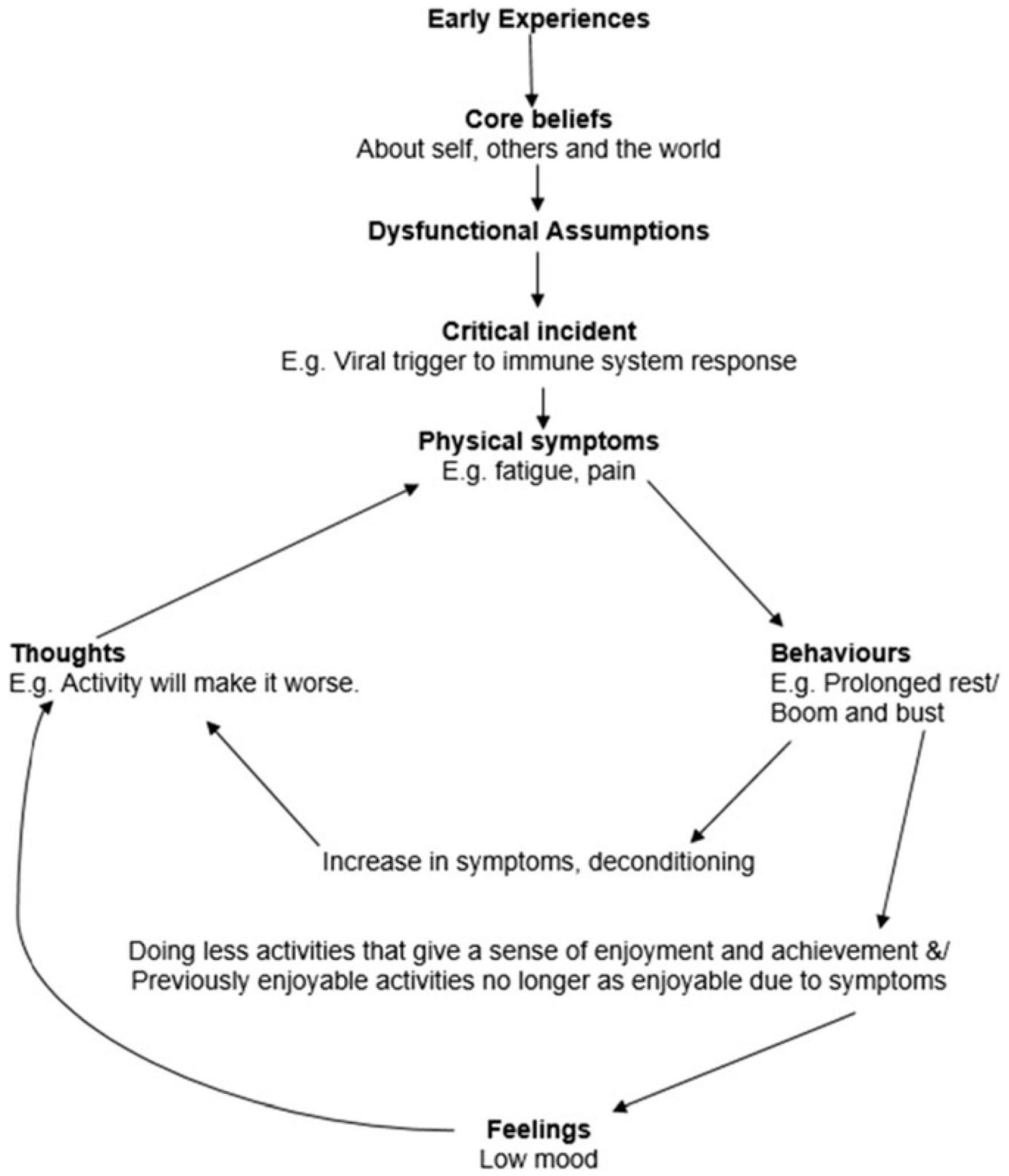

Figure 2.

Longitudinal formulation of CFS/ME (based on Browne and Chalder, 2006) 


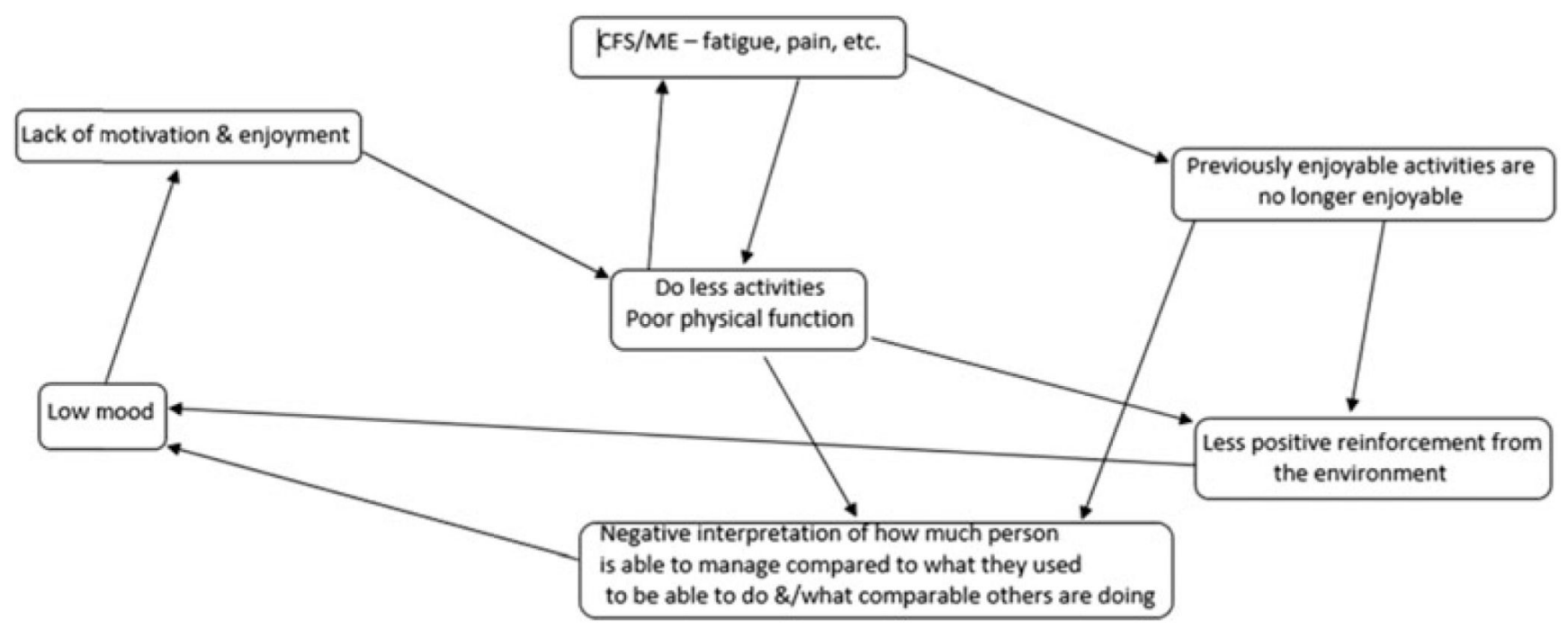

Figure 3.

Proposed maintenance cycle of CFS and low mood incorporating elements of the cognitive behavioural models of CFS/ME, Beckian cognitive model of depression and behavioural models of depression 


\section{Table 1}

Comparison of ICD-10 diagnostic criteria and NICE

\begin{tabular}{lll}
\hline & Depression & Chronic fatigue, unspecified \\
\hline Symptoms & $\begin{array}{l}\text { Depressed mood, loss of interest and enjoyment, and } \\
\text { reduced energy leading to increased fatigue and } \\
\text { reduction in activity levels. Also may experience poor } \\
\text { concentration and attention, lowered self-esteem and } \\
\text { self-confidence, guilt and unworthiness, negative and } \\
\text { hopeless views of the future, self-injurious behaviour } \\
\text { or suicidal ideation/attempts, disturbed sleep and } \\
\text { altered appetite }\end{array}$ & $\begin{array}{l}\text { Persistent/recurrent fatigue, and at least four of: general malaise } \\
\text { for }>24 \mathrm{~h} \text { after physical activity, muscle pain, joint pain, } \\
\text { problems with memory/concentration, headaches, sleep } \\
\text { disturbance, sore throat, tender lymph nodes. Symptoms are not } \\
\text { the result of ongoing exertion and are not relieved by rest }\end{array}$ \\
Functional impact & $\begin{array}{l}\text { Not explicitly stated, but reduction in activity } \\
\text { mentioned }\end{array}$ & $\begin{array}{l}\text { Substantial reduction of previous levels of occupational, } \\
\text { educational, social, or personal activities }\end{array}$ \\
Duration & At least 2 weeks & At least 6 months in adults \\
NICE & References ICD-10 criteria & $\begin{array}{l}\text { States that symptoms need to have been present for at least 3 } \\
\text { months in a child }\end{array}$ \\
\hline
\end{tabular}

Behav Cogn Psychother. Author manuscript; available in PMC 2018 March 01. 


\section{Table 2}

\section{Distinguishing factors of CBT-CFS versus CBT-D}

\begin{tabular}{lll}
\hline & CBT for CFS/ME & CBT for depression \\
\hline Formulation model & $\begin{array}{l}\text { Formulation is of CFS/ME symptoms primarily } \\
\text { (Browne and Chalder, 2006) }\end{array}$ & $\begin{array}{l}\text { Formulation is of depression primarily (Beckian } \\
\text { model) }\end{array}$ \\
Activity & $\begin{array}{l}\text { Activity focus is on boom-and-bust, monitoring } \\
\text { high energy activities, setting baseline, gradually } \\
\text { increasing level of activities }\end{array}$ & $\begin{array}{l}\text { Activity focus is on behavioural activation - } \\
\text { scheduling pleasant activities and activities that give a } \\
\text { sense of achievement, monitoring impact of these on } \\
\text { mood }\end{array}$ \\
Goals & $\begin{array}{l}\text { Most likely to involve decreasing fatigue and } \\
\text { related symptoms } \\
\text { Cognitive focus }\end{array}$ & $\begin{array}{l}\text { Most likely to involve improving mood, feeling } \\
\text { happier }\end{array}$ \\
Behavioural experiment targets & Cognitivity and physical symptoms, illness beliefs \\
Cognitions that contribute to avoidance of activity & $\begin{array}{l}\text { Cognitive focus is on depressive cognitions about self, } \\
\text { others and the world }\end{array}$ \\
Cognitions that contribute to the maintenance of low \\
mood
\end{tabular}

